\title{
Opção técnica para a síntese de grandes feridas da parede corpórea
}

\author{
Technical options for suturing large wounds of the corporeal wall
}

Andy Petroianu, TCBC-MG 1

\section{R E S U M O}

\begin{abstract}
As grandes feridas da parede corpórea, decorrentes de traumas extensos, retirada de tumores ou laparostomias prolongadas constituem um desafio cirúrgico de difícil solução. Neste trabalho o autor tem por finalidade mostrar que aproximação das bordas de grandes feridas, utilizando tira elástica de borracha mantidas sob tensão moderada é uma alternativa simples, eficaz e de custo mínimo, que pode ser utilizada em muitas circunstâncias cirúrgicas.
\end{abstract}

Descritores: Feridas grandes. Cicatrização de feridas. Síntese. Fechamento. Tira de borracha. Gominha. Tratamento.

\section{INTRODUÇÃO}

U $m$ dos grandes desafios cirúrgicos é o fechamento de grandes feridas, decorrentes de traumas maiores, retirada de tumores extensos ou procedimentos cirúrgicos, que deixam as bordas das feridas afastadas por um tempo prolongado, como as laparostomias ${ }^{1,2}$. Nessas situações, os retalhos de pele (diretos, ou com a utilização de vetores, ou após expansores cutâneos) e os musculocutâneos são as alternativas cirúrgicas mais utilizadas, com resultados, por vezes, insatisfatórios, mesmo quando realizados por cirurgiões plásticos experientes ${ }^{3,4}$. Outra opção é manter a ferida com curativo, até granular e cobri-la, em seguida, com enxerto de pele parcial ou total. Há ainda a possibilidade de cuidar da ferida até a aproximação espontânea das bordas ou sua cobertura natural por tecido fibroso. Para acelerar a aproximação das bordas de grandes feridas, têm sido propostas suturas progressivas ou a utilização de cintas, fitas adesivas, pesos, etc..$^{5-7}$.

O objetivo desta publicação é apresentar uma alternativa eficaz, simples e barata, para aproximar as bordas da ferida, por meio de tira elástica de borracha, suturada às bordas da ferida.

\section{TÉCNICA OPERATÓRIA}

Após a remoção, em três pacientes, de extensa tumoração da parede abdominal a aproximação das bordas opostas dessas feridas foi obtida por meio de tira circular elástica de borracha, conhecida como elástico ou gominha, que, entre outras funções, é habitualmente utilizada para conter maços de dinheiro em banco. Essas gominhas foram esterilizadas em autoclave.
Após a limpeza demorada das feridas com solução anti-séptica, suas bordas foram anestesiadas com lidocaína. Uma tira de borracha circular era suturada às bordas da ferida com fio de náilon 2-0. Iniciava-se a sutura com um ponto que englobava a gominha e um dos vértices da ferida. Em seguida, esse elástico era dobrado sobre si, para formar um X e cada lado dele era fixado com ponto às bordas da ferida. Essa tira de borracha foi consecutivamente dobrada em $X$ e outros pontos fixaram-na às bordas da ferida, até atingir-se o outro vértice. Os pontos da pele eram passados paralelamente à ferida, a cerca de um centímetro da borda, para evitar que o fio cortasse o tecido, pela tração do elástico.

Nos casos em que a ferida foi maior do que uma única gominha podia aproximar, uma segunda gominha complementou o procedimento. (Figuras 1B e 1C) Na experiência apresentada neste trabalho, não houve a necessidade de utilizar mais de dois elásticos de borracha.

Em curto período de tempo, houve a aproximação das bordas da ferida e, conseqüentemente, o elástico bambeava e perdia sua tensão de tração. Nessa situação, sob anestesia local, a tira de borracha foi tracionada entre os pontos, e foram dados novos pontos, para mantê-la com a tensão moderada. Durante esse procedimento, a segunda gominha, quando presente, era retirada. (Figura 1D) Nos casos em que o elástico se rompia, ele era substituído por outro novo e o procedimento era repetido.

As feridas receberam os cuidados diários habituais de limpeza com solução salina e proteção.

\section{RESULTADOS}

As feridas foram aproximadas muito satisfatoriamente. No início, os pacientes reclamaram de dor

Trabalho realizado no Departamento de Cirurgia Faculdade de Medicina da UFMG - MG-BR.

1. Professor Titular do Departamento de Cirurgia da Faculdade de Medicina, UFMG - MG-BR. 
e desconforto local, que foram resolvidos com analgesia com fármacos à base de dipirona. Em poucos dias, já não havia mais a necessidade de medicação. Os curativos simples foram suficientes para proteger as feridas.

O fechamento completo das feridas ocorreu em prazos que variaram entre um e 34 dias. Após a aproximação completa das bordas, a pele foi suturada com pontos separados de fio de náilon 3-0. A gominha foi retirada um dia após a sutura da pele. Logo após este procedimento os pacientes recebiam a alta hospitalar. Os pontos de pele foram retirados após três semanas. algum.

Não foram utilizados antibióticos em paciente

Todos os pacientes ficaram satisfeitos com o resultado obtido e nenhum deles solicitou correção plástica posterior, apesar de a maior parte das cicatrizes ter ficado alargada e com as marcas dos pontos laterais.
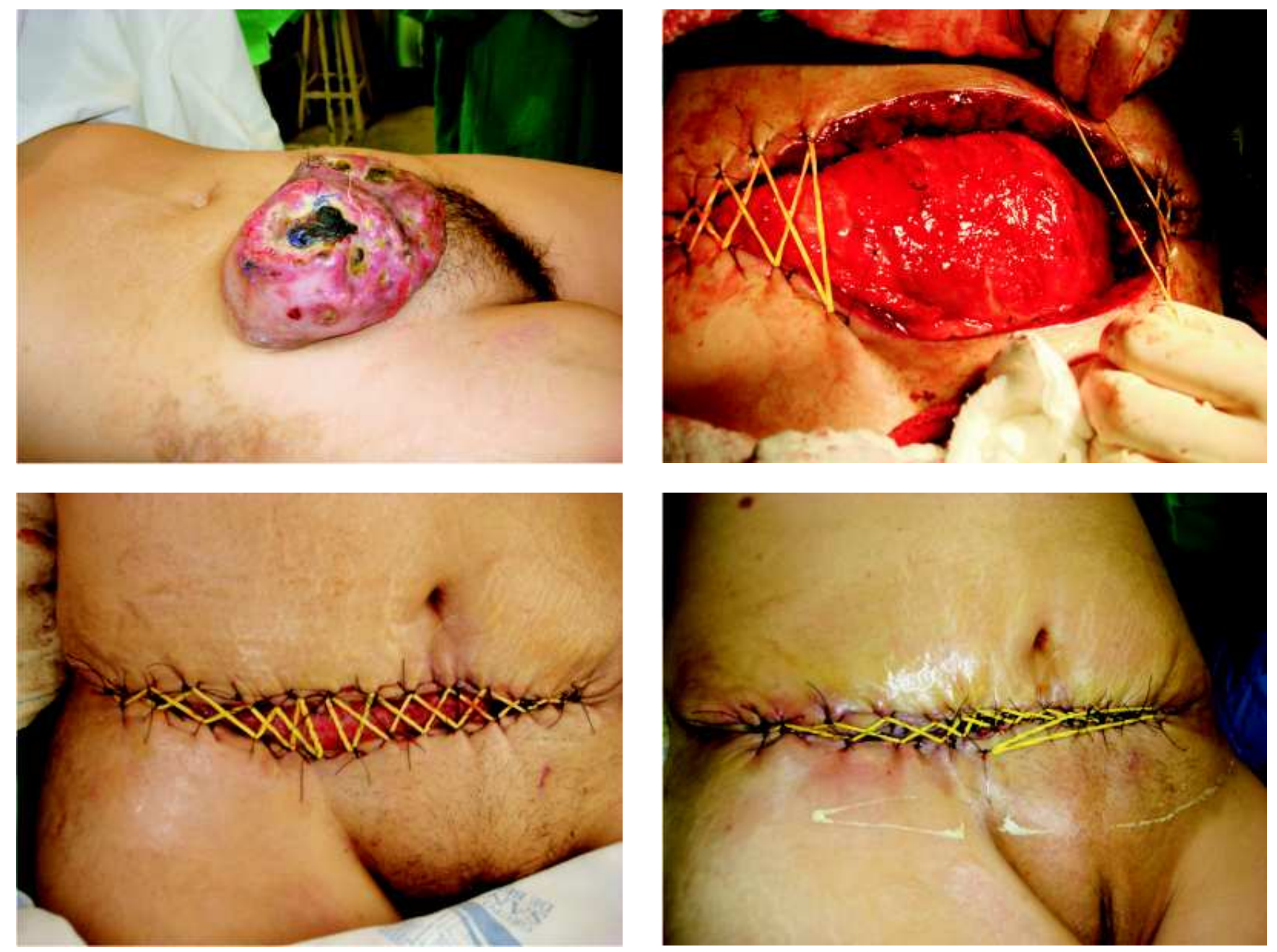

Figura 1 - Utilização de tiras elásticas de borracha para tratar uma grande ferida da parede abdominal, decorrente da retirada de um sarcoma de pele.

A - Grande tumor da parede inferior direita do abdome, que foi removido com ampla margem livre.

B - Colocação de duas tiras de borracha para aproximar as bordas da ferida.

C - Resultado obtido após dois dias.

D - Aspecto operatório no sétimo dia pós-operatório, com a retirada de uma das tiras de borracha e refixação da outra tira. 
sa, mas uma aplicação terapêutica de um método já descrito na literatura em outras situações, ${ }^{8}$ não houve seu registro em Comitê de Ética.

Tecnicamente, a aproximação das bordas com essa gominha é factível a todo cirurgião, mesmo aquele com pouca experiência. Essas tiras de borracha não têm custo quase algum e são disponíveis com grande facilidade. A maior atenção que se deve ter é com a tração moderada da gominha, para permitir uma tensão continua sobre a pele, sem lesá-la pelo trauma do ponto que a transfixa.
Quanto aos demais cuidados com a ferida, eles não excedem à rotina de limpeza e proteção adequadas.

A sutura da pele, após a aproximação das bordas pode ser dispensada, pois a união cutânea promove a cicatriz. No entanto, com os pontos adequadamente transpassados, evita-se a inversão da pele e o resultado estético é melhor.

Este relato sinaliza que a tira elástica de borracha circular (gominha) é um recurso eficaz, de fácil utilização, barato e muito disponível, que deve ser considerado para tratamento de grandes feridas da parede corpórea.

\title{
A $B$ S S T R A C $\mathrm{C}$
}

\begin{abstract}
Large wounds of the corporeal wall due to extensive traumas, tumor excisions or prolonged laparostomies are surgical challenges with difficult solutions. We show on this paper that wedge approximations of large wounds using elastic rubber band kept under moderate tension is a simple alternative, with great efficacious and low cost, that can be used in many surgical circumstances.
\end{abstract}

Key words: Large wound. Wound healing. Synthesis. Closure. Rubber strip. Elastic band. Treatment.

\section{REFERÊNCIAS}

1. Howdieshell TR, Proctor CD, Sternberg E, Cué Jl, Mondy JS, Hawkins ML. Temporary abdominal closure followed by definitive abdominal wall reconstruction of the open abdomen. Am J Surg. 2004; 188(3):301-6

2. Jernigan TW, Fabian TC, Croce MA, Moore N, Pritchard FE, Minard G, Bee TK. Staged management of giant abdominal wall defects: acute andlong-term results. Ann Surg. 2003; 238(3):349-355; discussion 355-7.

3. Miller PR, Thompson JT, Faler BJ, Meredith JW, Chang MC. Late fascial closure in lieu of ventral hernia:the nest step in open abdomen. J Trauma. 2002; 53(5):843-9.

4. Cipolla J, Stawicki SP, Hoff WS, McQuay N, Hoey BA, Wainwright $\mathrm{G}$, Grossman MD. A proposed algorithm for managing the open abdomen. Am Surg. 2005; 71(3):202-7.

5. Fansler RF, Taheri P, Cullinane C, Sabates B, Flint LM. Polypropylene mesh closure of the complicated abdominal wound. Am J Surg. 1995; 170(1):15-8.

6. Weinberg JA, George RL, Griffin RL, Stewart AH, Reiff DA, Kerby JD et al. Closing the open abdomen: improved success with
Wittmann Patch staged abdominal closure. J Trauma. 2008: 65(2):345-8.

7. Petersson U, Acosta S, Björck M. Vacuum-assisted wound closure and mesh-mediated fascial tract open abdomen. World J Surg. 2007: 31(11): 2133-7.

8. Raskin KB. Acute vascular injuries of the upper extremity. Hand Clin. 1993; 9(1):115-30.

Recebido em 20/12/2008

Aceito para publicação em 20/03/2009

Conflito de interesse: nenhum

Fonte de financiamento: nenhuma

\section{Como citar este artigo:}

Petroianu A. Opção técnica para a síntese de grandes feridas da parede. Rev Col Bras Cir. [periódico na Internet] 2009; 36(4). Disponível em URL: http://www.scielo.br/rcbc

\section{Endereço para correspondência:}

Prof. Andy Petroianu

E-mail: petroian@gmail.com 